\title{
Labial Biopsy of Minor Salivary Glands: Indications in Clinical Diagnostics
}

\author{
Frédérick Gaultier ${ }^{1}$, Ishaï Yaacov Y Sitbon ${ }^{1}$ and Bruno Gogly*1,2 \\ ${ }^{1}$ Henri Mondor Hospital, Dental Department, France \\ ${ }^{2}$ Laboratory of Molecular Oral Pathophysiology, Paris \\ *Corresponding author: Bruno GOGLY, Odontology Department, Henri Mondor Hospital, France
}

\begin{tabular}{|c|c|}
\hline ARTICLE INFO & ABSTRACT \\
\hline $\begin{array}{l}\text { Received: 幽 February 26, } 2019 \\
\text { Published: 业 March 08, } 2019\end{array}$ & $\begin{array}{l}\text { Keywords: Labial biopsy of Minor Salivary Gland (LMSBG); Diagnostic; Systemic Patholo- } \\
\text { gies }\end{array}$ \\
\hline
\end{tabular}

Citation: Frédérick G, Ishaï Yaacov Y S, Bruno G. Labial Biopsy of Minor Salivary Glands: Indications in Clinical Diagnostics. Biomed J Sci \& Tech Res 15(4)-2019. BJSTR. MS.ID.002738.

\section{Introduction}

The Labial Biopsy of the Salivary Minor Glands (LMSGB) is a complementary examination frequently performed in oral surgery since 1968 [1]. It participates in the diagnosis of many systemic pathologies including autoimmune diseases, amyloidosis, sarcoidosis, lupus erythematosus, Parkinson's and tuberculosis [28]. The plurality of pathologies involved, associated with a significant sensitivity and specificity of this additional examination justify its frequency of implementation. We discuss the different pathologies for which this complementary examination is requested.

\section{LMSGB and Systemic Pathologies}

The LMSGB participates in the diagnosis of many systemic pathologies, and may allow early diagnosis, diagnostic orientation or confirmation of a presumptive diagnosis based on clinical symptoms. This examination may also support conventional diagnostic. Amyloidosis is a rare disease due to a deposition of proteins that present a conformational defect resulting in the formation of amyloid fibrils. Its prevalence is unknown although estimated at $1 / 100000$. More than twenty different proteins can be involved in the formation of these deposits, which is why it is more accurate to talk about amyloidosis. The majority of amyloidosis are generalized or diffuse multi-systemic diseases. The main organs affected are the kidney, the heart, the digestive tract, the liver, the skin, the peripheral nerves, the eye. The evolution is most often severe, with destruction of affected organs. There are also some localized forms. The most common forms are AL (immunoglobulin), AA (inflammatory) and ATTR (transthyretin) amyloidosis. The presence of fibrillar amyloid protein during salivary gland biopsy is performed by Congo Red or Crystal Violet stains [9-11]. This additional examination has a very high sensitivity (83\%) and a positive predictive value of $100 \%$ [12]. Sjogren's syndrome or sicca syndrome is an autoimmune pathology characterized by dry eye and buccal (xerophthalmia, xerostomia) related to inflammation of the exocrine glands and the prevalence is 1-5 / 10000 [13]. The biopsy makes it possible to highlight the presence of numerous markers or inflammatory factors such as: B-Cell Activator Factor (BAFF), B-Cell Activator Factor Receptor (BAFF + R), CXC Motif Chemokine Ligand 13, chemoattractant B-lymphocyte, B-cell attracting chemokine-1 (CXCL13), Chemokine receptor type 5 (CXCR5), Fk-Like tyrosine kinase 3 (Flt3), Fk-like tyrosine kinase 3flt-3 ligand (FLT-3L), Interleukin 6 (IL-6), Interleukin 6 Receptor (IL-6R), Interleukin 22 (IL-22) Interleukin 22 Receptor (IL-22R) [14].

All these markers confirm the suspected diagnosis based on clinical observation. LMSGB has a sensitivity and specificity of $80 \%$ for Gougerot-Sjogren Syndromes but decreases with age since there are many cases of false positives in elderly patients [15]. Mucosa Associated Lymphoid Tissue (MALT) [16] lymphoma is a rare form of non-Hodgkin's lymphoma that affects B cells and lymphoid tissue 
associated with mucous membranes. It develops preferentially on grounds favorable to autoimmune pathologies or following a bacterial infection. Its prevalence is 1-9 / 100,00 [17]. Some cases of B-MALT Lymphoma are diagnosed during a LMSGB performed in the context of Sjögren's syndrome [18]. LMSGB biopsy showed atypical diffuse infiltration by mononuclear cells of variable size and atypical nuclei affecting the whole specimen with destruction of glandular architecture, leading to a diagnosis of B-cell MALT lymphoma [19]. Thus 5\% of patients with Sjogren's develop MALT lymphoma [14]. Rheumatoid arthritis is an autoimmune pathology that develops in $50 \%$ of cases in patients with a genetic predisposition. This disease is characterized by persistent synovitis and systemic inflammation. Its prevalence is 0.5 to $1 \%$ of the adult population with 5 to $50 / 100,000$ new cases per year [20]. The symptoms of dry syndrome (Sjögren) in patients with rheumatoid arthritis are quite common.

This has been demonstrated by negative biopsies for Sjögren's syndrome while the diagnosis of rheumatoid arthritis was made. All biopsies were immunohistochemically evaluated for the presence and distribution of specific leukocyte subsets using appropriate markers and for the expression of certain immunoregulatory molecules by salivary gland epithelial cells [21]. Thus, one could consider an interest of the LMSBG for the differential diagnosis between rheumatoid arthritis and Sjögren. Systemic lupus is an autoimmune disease that begins with cutaneous manifestations (lupus erythematosus) and evolves by affecting many organs (systemic lupus erythematosus). It is related to a production of autoantibodies directed against nuclear and cytoplasmic antigens. This rare disease (less than 1/100000) can affect the skin, kidneys, joints, lungs and nervous system. The pathology alternates remissions and acute crises. There is no curative treatment, the drugs prescribed are intended to reduce inflammation and associated symptoms [22,23]. In Lupus Erythematosus, LMSBGs established xerostomia as a symptom of this condition without systematic association with Sjogren's syndrome. Histological examination of the minor salivary glands shows the presence of hyalinization and thickening of ductal membrane, perivascular inflammatory infiltrate, epithelial spongiosis with no ductal lymphocytic aggression, vacuolar degeneration of the ductal cells and acinar serous metaplasia.

Thus, the LMSBG allows a diagnostic orientation of Lupus Erythematosus [24]. Sarcoidosis is a multi-systemic disease of unknown cause characterized by the formation of immune granulomas in the affected organs. All organs may be affected, but pulmonary involvement is predominant. Other severe manifestations are cardiac, neurological, ocular, renal or laryngeal. X-ray of the lungs is abnormal in $90 \%$ of cases and reveals pulmonary infiltrates with or without fibrosis. With a prevalence of 1-5 / 10,000 , the associated mortality remains between 0.5 and $5 \%$ [25]. Although LMSBG is not recognized as a reliable complementary examination for the primary diagnosis of sarcoidosis, it provides a reliable differential diagnosis between Sjögren and Sarcoidosis and therefore appropriate management [26]. The diagnosis of Sarcoidosis with LMSBG is based on the presence of tuberculoid granulomas without caseous necrosis. The LMSBG appears as a key diagnostic confirmatory test before a possible treatment [4]. Tuberculosis is an infectious disease caused by the bacterium Mycobacterium tuberculosis, contagious, with varying clinical signs. It is the leading infectious cause of death globally [27]. A recent study has highlighted the low sensitivity of the LMSBG for the diagnosis or even the diagnostic orientation of tuberculosis [8].

However, this study of 65 patients with diagnosed tuberculosis was able to demonstrate the presence of granulomas in the LMSBG comparable to those found in 20 to $60 \%$ of cases of Sarcoidosis [28]. Thus, the vigilance to make a clear differential diagnosis between tuberculosis and sarcoidosis is essential, taking corticosteroids (treatment of sarcoidosis) can be fatal in case of tuberculosis. Neurological diseases are now the leading cause of disability and the second leading cause of death in the world [29]. Among them, Parkinson's disease has more than doubled since 1990. Parkinson's disease is a neurodegenerative pathology related to the degeneration of dopaminergic neurons. It is mainly manifested by a drop in postural stability, tremors, motor rigidity, although many other symptoms can be associated [30,31]. Recent studies indicate an interest in LMSBG as a confirmation element for early diagnosis of Parkinson's disease since it is found in $69 \%$ of patients diagnosed with alpha-synuclein in peri-acinar areas [7]. Although Alpha Synuclein is physiologically present in the brain, Parkinson's disease is found in other tissues or around nerve endings of the trigeminal nerve.

\section{Conclusion}

To conclude, biopsy of the minor salivary glands is a simple surgical procedure that is indicated in the confirmation or diagnosis of many pathologies. However, the number of glands to be collected and the method of preservation (paraformaldehyde, freezing, physiological fluid) must be indicated according to the anatomopathological analysis technique. In fact, antibody labeling is often not compatible with formalin fixation, unlike histological staining.

\section{References}

1. Alexander Langerman, Elizabeth A (2008) Blair Labial minor salivary gland biopsy. Operative Techniques in Otolaryngology 19(4): 248-251.

2. Wicheta S, Van der Groen T, Faquin WC, August M (2017) Minor Salivary Gland Biopsy-An Important Contributor to the Diagnosis of Sjögren Syndrome. J Oral Maxillofac Surg 75(12): 2573-2578.

3. De Paula Eduardo F, de Mello Bezinelli L, de Carvalho DL, Della Guardia B, de Almeida MD, et al. (2017) Minor salivary gland biopsy for the diagnosis of familial amyloid polyneuropathy. Neurol Sci 38(2): 311-318.

4. Blaise P, Fardeau C, Chapelon C, Bodaghi B, Le Hoang P (2011) Minor salivary gland biopsy in diagnosing ocular sarcoidosis. Br J Ophthalmol 95(12): 1731-1734. 
5. Bologna SB, Nico MMS, Florezi G, Cavalcante WS, Lourenço SV (2018) Peculiar histopathological features in minor salivary gland in lupus erythematosus. Lupus 27(10): 1706-1711.

6. Carletti R, Campo F, Fusconi M, Pellicano C, De Vincentiis M, et al. (2017) Phosphorylated $\alpha$-synuclein immunoreactivity in nerve fibers from minor salivary glands in Parkinson's disease. Parkinsonism Relat Disord 38: 99-101.

7. Gao L, Chen H, Li X, Li F, Ou Yang Q, et al. (2015) The diagnostic value of minor salivary gland biopsy in clinically diagnosed patients with Parkinson's disease: comparison with DAT PET scans. Neurol Sci 36(9): 1575-1580.

8. Delcey V, Morgand M, Lopes A, Mouly S, Jarrin I, Sellier P, et al. (2016) Prevalence of granulomatous lesions in minor salivary gland biopsy in a case series of 65 patients with tuberculosis. Rev Med Interne 37(2): 80-83.

9. Mollee P, Renaut P, Gottlieb D, Goodman H (2014) How to diagnose amyloidosis. Intern Med J 44(1): 7-17.

10. Jaccard A, Desport E, Mohty D, Bridoux F (2015) [AL amyloidosis]. Rev Med Interne 36(2): 89-97.

11. Iadanza MG, Jackson MP, Hewitt EW, Ranson NA, Radford SE (2018) A new era for understanding amyloid structures and disease. Nat Rev Mol Cell Biol 19(12): 755-773.

12. Sacsaquispe SJ, Antúnez de Mayolo EA, Vicetti R, Delgado WA (2011) Detection of AA-type amyloid protein in labial salivary glands. Med Oral Patol Oral Cir Bucal 16(2): 149-152.

13. Both T, Dalm VA, van Hagen PM, van Daele PL (2017) Reviewing primary Sjögren's syndrome: beyond the dryness - From pathophysiology to diagnosis and treatment. Int J Med Sci 14(3): 191-200.

14. Navarro Mendoza EP, Aguirre Valencia D, Posso Osorio I, Correa Forero SV, Torres Cutiva DF, et al. (2018) Cytokine markers of B lymphocytes in minor salivary gland infiltrates in Sjögren's syndrome. Autoimmun Rev 17(7): 709-714.

15. Guellec D, Cornec D, Jousse Joulin S, Marhadour T, Marcorelles P, et al. (2013) Diagnostic value of labial minor salivary gland biopsy for Sjögren's syndrome: a systematic review. Autoimmun Rev 12(3): 416420.

16. Du MQ (2016) MALT lymphoma: A paradigm of NF- $\kappa B$ dysregulation. Semin Cancer Biol 39: 49-60.

17. Violeta Filip P, Cuciureanu D, Sorina Diaconu L, Maria Vladareanu A, Silvia Pop C (2018) MALT lymphoma: epidemiology, clinical diagnosis and treatment. J Med Life 11(3): 187-193.

\section{ISSN: 2574-1241}

DOI: 10.26717/BJSTR.2019.15.002738

Bruno GOGLY. Biomed J Sci \& Tech Res

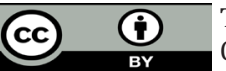

This work is licensed under Creative

Commons Attribution 4.0 License

Submission Link: https://biomedres.us/submit-manuscript.php
18. Van Mello NM, Pillemer SR, Tak PP, Sankar V (2005) B cell MALT lymphoma diagnosed by labial minor salivary gland biopsy in patients screened for Sjögren's syndrome. Ann Rheum Dis 64(3): 471-473.

19. Keszler A, Adler LI, Gandolfo MS, Masquijo Bisio PA, Smith AC, et al. (2013) MALT lymphoma in labial salivary gland biopsy from Sjögren syndrome : importance of follow-up in early detection. Oral Surg Oral Med Oral Pathol Oral Radiol 115(3): e28-33.

20. Scott DL, Wolfe F, Huizinga TW (2010) Rheumatoid arthritis. Lancet 376 (9746): 1094-1098.

21. Fragoulis GE, Fragkioudaki S, Reilly JH, Kerr SC, McInnes IB, et al. (2016) Analysis of the cell populations composing the mononuclear cell infiltrates in the labial minor salivary glands from patients with rheumatoid arthritis and sicca syndrome. J Autoimmun 73 : 85-91.

22. Fortuna G, Brennan MT (2013) Systemic lupus erythematosus: epidemiology, pathophysiology, manifestations, and management. Dent Clin North Am 57(4): 631-655.

23. Zhang H, Chambers W, Sciascia S, Cuadrado MJ (2016) Emerging therapies in systemic lupus erythematous: from clinical trial to the real life. Expert Rev Clin Pharmacol 9(5): 681-694.

24. Bologna SB, Nico MMS, Florezi G, Cavalcante WS, Lourenço SV (2018) Peculiar histopathological features in minor salivary gland in lupus erythematosus. Lupus 27(10): 1706-1711.

25. Giotaki H, Constantopoulos SH, Papadimitriou CS, Moutsopoulos HM (1986) Labial minor salivary gland biopsy: a highly discriminatory diagnostic method between sarcoidosis and Sjögren's syndrome. Respiration 50(2): 102-107.

26. Valeyre D, Prasse A, Nunes H, Uzunhan Y, Brillet PY, et al. (2014) Sarcoidosis. Lancet 383(9923): 1155-67.

27. (2018) Global Tuberculosis Report 2018. ISBN 978-92-4-156564-6. World Health Organization

28. Harvey J, Catoggio L, Gallagher PJ, Maddison PJ (1989) Salivary gland biopsy in sarcoidosis. Sarcoidosis 6(1): 47-50.

29. (2017) GBD 2015 Neurological Disorders Collaborator Group. Global, regional, and national burden of neurological disorders during 19902015: A systematic analysis for the Global Burden of Disease Study 2015. Lancet Neurol 16(11): 877-97.

30. Gazewood JD, Richards DR, Clebak K (2013) Parkinson disease: an update. Am Fam Physician 87(4): 267-273.

31. Capriotti T, Terzakis K (2016) Parkinson Disease. Home Health Now 34(6): 300-307.

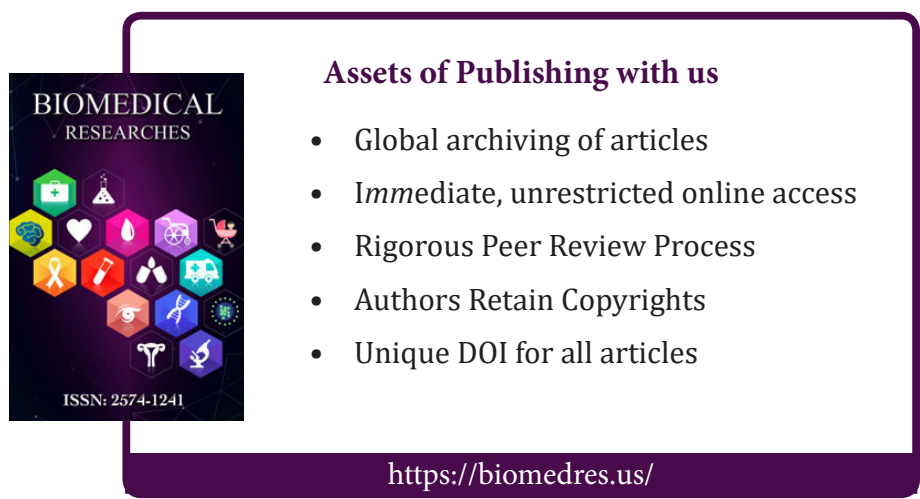

Copyright@ Bruno GOGLY| Biomed J Sci \& Tech Res| BJSTR. MS.ID.002738. 